\title{
Mesogenic Terminal Naphthyl Derivatives with Azomethine/Azo and Ester Central Linkages
}

\author{
H. N. Patel ${ }^{a}$ and A. K. Prajapati ${ }^{\star, b}$ \\ ${ }^{a}$ Shree Maneklal M. Patel Institute of Sciences \& Research, Sector 15/23, Gandhinagar, \\ Kadi Sarva Vishwavidhyalaya, Gandhinagar, India \\ ${ }^{b}$ Department of Chemistry, Faculty of Science, The M. S. University of Baroda, Vadodara-390002, India
}

Email: akprajapati@yahoo.co.uk (A. K. P.)

\begin{abstract}
Two new mesogenic homologous series of naphthalene with different central linkages: $(E)$-naphthalen-2-yl 4-(4-n-alkoxybenzylideneamino)benzoate (I) and (E)-naphthalen-2-yl 4-(4-n-alkoxyphenylazo)benzoate (II) have been synthesized and characterized by a combination of elemental analysis and standard spectroscopic methods. In series I, all the twelve synthesized compounds exhibit mesomorphism. Methoxy to $n$-tetradecyloxy derivatives exhibit enantiotropic nematic mesophase. The SmA mesophase commences from $n$-pentyloxy derivative as an enantiotropic and persists up to the $n$-hexadecyloxy homologue synthesized. In series II, all the twelve synthesized compounds exhibit enantiotropic nematic mesophase. SmA mesophase commences from $n$-heptyloxy as monotropy and persist up to the $n$-hexadecyloxy homologous synthesized. The mesomorphic properties of present series were compared with each other and with a structurally related mesogenic homologous series to evaluate the effects of central linkage on mesomorphism.
\end{abstract}

Keywords naphthalene, azomethine ester, azoester, nematic, smectic A

\section{Introduction}

A vast number of mesogenic naphthalene derivatives are reported in the literature ${ }^{[1,2]}$ as naphthalene derivatives exhibit rich mesomorphism if properly designed. Weygand ${ }^{[3]}$ reported several mesogenic Schiff bases of 2,6-, 1,5-, and 1, 4-diaminonaphthalenes. Gray and Jones ${ }^{[4]}$ investigated liquid crystalline (LC) properties of different alkoxy naphthoic acids. Coates and Gray ${ }^{[5]}$ synthesized 4-n-alkyl/alkoxyphenyl esters of 6-n-alkyl/alkoxy naphthalene-2-carboxylic acids. Dave and others studied a variety of LC naphthalene derivatives such as alkoxy benzoates of 1,5- and 1,4dihydroxynaphthalene, ${ }^{[6]}$ esters of cholesterol ${ }^{[7]}$ and alkoxy naphthyliedene Schiff bases, ${ }^{[8-10]}$ exhibiting smectic, nematic and cholesteric mesomorphism. Malthete et al. ${ }^{[11]}$ synthesized tetra acylated 1,4,5,8-tetera hydroxyl naphthalene derivatives, which may be looked upon as "conjoined twin" mesogens. Hsu et al. ${ }^{[12]}$ reported the LC materials, 1,4-bis (6-n-alkoxyl-2-naphthyl)-1,3-butadiynes, to probe the effects of terminal chains on the mesophase transition temperatures, when compared with those of the analogous compounds without chains. The synthesis and mesomorphic properties of banana shaped compounds derived from 2,7-dihydroxy naphthalene have also been reported. ${ }^{[13-17]}$ Rahman et al. ${ }^{[18]}$ have reported new pyrimidine-based photo-switchable bentcore liquid crystals.

Earlier, we have reported mesogenic homologous series of Schiff base esters containing the naphthalene moiety and studied the effect of lateral thiol ${ }^{[19]}$ and methoxy ${ }^{[20]}$ substituents on mesomorphism. We have also reported the synthesis of mesogenic homologous series of azomesogens without lateral substituent, ${ }^{[21]}$ with lateral methyl ${ }^{[22]}$ and chloro ${ }^{[23]}$ groups, and evaluated the effect of lateral methyl as well as chloro groups on mesomorphism. We have synthesized a mesogenic homologous series of azo esters containing two naphthalene nuclei $i^{[24]}$ and studied the effect of the naphthalene moiety on mesomorphism. We $e^{[25]}$ have also prepared a mesogenic homologous series of Schiff base cinnamates comprising a naphthalene moiety, and studied the effect of cinnamoyl linkage $(\mathrm{CH}=\mathrm{CH}-\mathrm{COO})$ as well as naphthaalene moiety on LC properties.

The salicylaldimine fragment is well recognized as a good mesogen in liquid crystalline materials because the azo methane linkage is stabilized by intra-molecular hydrogen bonding, and it has the ability to coordinate with the metals. ${ }^{[26,27]}$ The incorporation of transition metals into LC has led to the study of interesting magnetic, electronic and optical properties in mesomorphic materials. ${ }^{[28-31]}$ Hence, we ${ }^{[32]}$ have reported two new mesogenic homologous series of salicylaldimines with the naphthalene moiety, viz. 5-n-alkoxy2-((E)-(naphthalen-2-ylimino)methyl)phenols and 3-hydroxy-4$((E)$-(naphthalen-2-ylimino)methyl)phenyl 4- $n$-alkoxybenz-oates, as well as metallomesogens of both series of ligands containing the $\mathrm{Cu}(\mathrm{II})$ atom, and have examined the phase transition behavior of these compounds. We have observed that the incorporation of a metal centre into the ligand molecule leads to more ordered Cu-complex mesophases with very high thermal stabilities.

Naphthalene ring is an interesting aromatic core for the synthesis of LC compounds. It increases the breadth of the molecules, which can decrease the mesogenic properties. However, the naphthyl derivative may exhibit rich mesomorphism. Recently, we ${ }^{[33]}$ have synthesized two new mesogenic homologous series havingcinnamoyl \& ester central linkages and studied the effect of cinnamoyl central linkage on the mesomorphic properties. In the present investigation, two new 
mesogenic homologous series of azomethine/azo esters are synthesized. The purpose of synthesis is to continue the search for new mesogenic compounds containing a naphthalene moiety and to study the effect of naphthalene moiety and different central linkages on mesomorphism.

\section{Experimental}

\section{Materials and methods}

4-Aminobenzoic acid, 4-hydroxybenzaldehyde, 1-bromoalkane, potassium hydroxide $(\mathrm{KOH})$, potassium carbonate $\left(\mathrm{K}_{2} \mathrm{CO}_{3}\right)$, hydrochloric acid $(\mathrm{HCl})$, thionyl chloride $\left(\mathrm{SOCl}_{2}\right)$, 2-naphthol, dicyclohexylcarbodiimide (DCC), 4-dimethylaminopyridine (DMAP), tetrahydrofuran (THF), and ethanol were used as received. Solvents were dried and distilled before use. Microanalysis of the compounds was performed on a Coleman carbon-hydrogen analyzer, and the values obtained are in close agreement with those calculated. IR spectra were determined for $\mathrm{KBr}$ pellets using a Shimadzu IR-408 spectrophotometer. ${ }^{1} \mathrm{H}$ NMR spectra were obtained with a Perkin-Elmer R-32 spectrometer using tetramethylsilane (TMS) as internal reference standard. The chemical shifts are quoted as $\delta$ (ppm) downfield from the reference and $\mathrm{CDCl}_{3}$ as solvent. The phase assignments and transition temperatures were determined by thermal polarizing optical microscopy (Leitz Laborlux $12 \mathrm{POL}$ ) equipped with a heating stage (Linkam Scientific Instruments Ltd., T95-HS). The enthalpies of transitions are reported in $\mathrm{J} \cdot \mathrm{g}^{-1}$ and they were measured on a differential scanning calorimeter (Mettler TA-4000) at a rate of $5^{\circ} \mathrm{C} \cdot \mathrm{min}^{-1}$. The instrument was calibrated using pure indium as a standard.

\section{Synthesis of series I and II compounds}

The synthetic route to compounds of series I and II is illustrated in Scheme 1.

Scheme 1 Synthetic route to series I and II compounds.

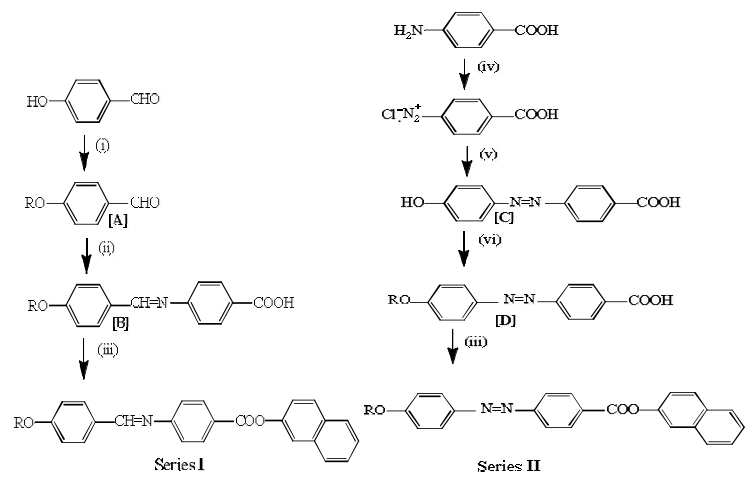

Reagents and conditions: (i) $\mathrm{R}-\mathrm{Br}$, anhydrous $\mathrm{K}_{2} \mathrm{CO}_{3}$, dry acetone; (ii) 4-Aminobenzoic acid in hot ethanol, few drops of acetic acid; (iii) 2-Napthol, DCC, DMAP, dry THF; (iv) $\mathrm{NaNO}_{2}, \mathrm{HCl}, 0-5{ }^{\circ} \mathrm{C}$; (v) Phenol in $\mathrm{NaOH}, 0-10{ }^{\circ} \mathrm{C}$; (vi) R-Br, ethanol, $\mathrm{KOH}$.

4-n-Alkoxybenzaldehydes [A] were prepared by the method of Gray and Jones. ${ }^{[34]}(E)-4$-(4-n-alkoxybenzylideneamino)benzoic acids [B] were synthesized by condensing equimolar quantities of 4-n-alkoxybenzaldehydes and 4-aminobenzoic acid in boiling ethanol. ${ }^{[35]}$ For the preparation of series I compound $0.1 \mathrm{~mol}$ [B], $0.1 \mathrm{~mol}$ of 2-naphthol, $0.1 \mathrm{~mol}$ of DCC and 0.01 mol of DMAP were dissolved in dry THF and stirred at room temperature for overnight. ${ }^{[36]}$ The insoluble solid was removed through filtration. All the compounds of the present series I were synthesized with the same method.
(E)-4-(4-hydroxyphenylazo)benzoic acid [C] and (E)-4-(4-nalkoxyphenylazo)benzoic acids [D] were synthesized following the method of Jadav. ${ }^{[37]}$ All the alkoxyazo acids [D] were crystallized several times from ethanol or acetic acid until constant transition temperatures were obtained. The transition temperatures are in good accordance with the literature. ${ }^{[37]}$ Yield is in general $70 \%-75 \%$. All the compounds of series II were synthesized from [D] and 2-naphthol using DCC and DMAP following the procedure described for the preparation of series I compound.

All the compounds of both the series were crystallized from ethanol until constant transition temperatures were obtained (Table 1).

Both the micro analytical and spectroscopic data obtained for all the compounds of series I \& II were found to be consistent with the proposed structure. Data of $n$-octyloxy and $n$-hexadecyloxy derivatives of both the series as representative members are given below (see Supporting Information for spectrum)

\section{Series I}

(E)-naphthalen-2-yl 4-(4-n-octyloxybenzylideneamino) benzoate: UV-Vis (MDC) $\lambda_{\text {max: }}: 325 \mathrm{~nm} ;{ }^{1} \mathrm{H}$ NMR $\left(\mathrm{CDCl}_{3}, 400 \mathrm{MHz}\right)$ $\delta: 0.90\left(t, 3 \mathrm{H}, J=6.6 \mathrm{~Hz}, \mathrm{CH}_{3}\right), 1.30-1.60\left(\mathrm{~m}, 10 \mathrm{H}, 5 \times \mathrm{CH}_{2}\right)$, $1.86\left(\mathrm{q}, 2 \mathrm{H}, J=6.7 \mathrm{~Hz}, \mathrm{Ar}-\mathrm{O}-\mathrm{C}-\mathrm{CH}_{2}\right), 4.03(\mathrm{t}, 2 \mathrm{H}, J=6.9 \mathrm{~Hz}$, $\left.\mathrm{O}-\mathrm{CH}_{2}\right), 6.95(\mathrm{~d}, 2 \mathrm{H}, \mathrm{J}=8.8 \mathrm{~Hz}, \mathrm{Ar}-\mathrm{H}$ at C-3' and C-5'), 7.38 (d $2 \mathrm{H}, J=8.6 \mathrm{~Hz}$, naphthalene ring system at C-3" and C-4"), $7.48-7.51(\mathrm{~m}, 4 \mathrm{H}$ of naphthalene ring system at C-5", C-6", C-7" and C-8"), 7.65 (s, $1 \mathrm{H}$ of naphthalene ring system at C-1"), 7.86-7.92 (m, 4H, Ar-H at C-2, C-6, C-2' and C-6'), $8.26(\mathrm{~d}, 2 \mathrm{H}$, $J=8.8 \mathrm{~Hz}, \mathrm{Ar}-\mathrm{H}$ at $\mathrm{C}-3$ and $\mathrm{C}-5), 8.39(\mathrm{~s}, 1 \mathrm{H}, \mathrm{CH}=\mathrm{N})$; IR $(\mathrm{KBr}) v$ : 2929, 1724 (COO), 1627, $1597(\mathrm{CH}=\mathrm{N}), 1512,1425,1273$, $1168,889,817,744 \mathrm{~cm}^{-1}$. Anal. calcd for $\mathrm{C}_{32} \mathrm{H}_{33} \mathrm{O}_{3} \mathrm{~N}: \mathrm{C} 80.16, \mathrm{H}$ 6.88, N 2.92; found C 80.15, H 6.89, N 2.95 .

(E)-naphthalen-2-yl 4-(4-n-hexadecyloxybenzylideneamino) benzoate: ${ }^{1} \mathrm{H}$ NMR $\left(\mathrm{CDCl}_{3}, 400 \mathrm{MHz}\right) \delta .0 .92(\mathrm{t}, 3 \mathrm{H}, J=6.4 \mathrm{~Hz}$, $\left.\mathrm{CH}_{3}\right), 1.23-1.59\left(\mathrm{~m}, 26 \mathrm{H}, 13 \times \mathrm{CH}_{2}\right), 1.85(\mathrm{q}, 2 \mathrm{H}, J=6.6 \mathrm{~Hz}$, Ar-O-C- $\mathrm{CH}_{2}$ ), 4.09 (t, $\left.2 \mathrm{H}, J=6.8 \mathrm{~Hz}, \mathrm{O}-\mathrm{CH}_{2}\right), 7.07$ (d, 2H, J = $8.7 \mathrm{~Hz}, \mathrm{Ar}-\mathrm{H}$ at $\mathrm{C}-3^{\prime}$ and $\left.\mathrm{C}-5^{\prime}\right), 7.3(\mathrm{~d}, 2 \mathrm{H}, J=8.9 \mathrm{~Hz}$, naphthalene ring system at C-3" and C-4"), 7.45-7.59 (m, $4 \mathrm{H}$ of naphthalene ring system at C-5", C-6", C-7" and C-8"), 7.70 (s, $1 \mathrm{H}$ of naphthalene ring system at $\mathrm{C}-1$ "), $7.80-7.90(\mathrm{~m}, 4 \mathrm{H}, \mathrm{Ar}-\mathrm{H}$ at C-2, C-6, C-2' and C-6'), 8.27 (d, 2H, J = 8.9 Hz, Ar-H at C-3 and $\mathrm{C}-5), 8.42(\mathrm{~s}, 1 \mathrm{H}, \mathrm{CH}=\mathrm{N})$; IR ( $\mathrm{KBr})$ v: 2929, 1724 (COO), 1627, $1591(\mathrm{CH}=\mathrm{N}), 1510,1411,1260,1165,889,813,744$ $\mathrm{cm}^{-1}$. Anal. calcd for $\mathrm{C}_{40} \mathrm{H}_{49} \mathrm{O}_{3} \mathrm{~N}$ : C 81.21, H 8.29, N 2.36; found C 81.25, H 8.2, N 2.31.

\section{Series II}

(E)-naphthalen-2-yl 4-(4-n-octyloxyphenylazo)benzoate: UV-Vis (MDC) $\lambda_{\text {max }}: 260 \mathrm{~nm} ;{ }^{1} \mathrm{H}$ NMR $\left(\mathrm{CDCl}_{3}, 400 \mathrm{MHz}\right) \delta: 0.90$ (t, $\left.3 \mathrm{H}, J=6.4 \mathrm{~Hz}, \mathrm{CH}_{3}\right), 1.20-1.76\left(\mathrm{~m}, 10 \mathrm{H}, 5 \times \mathrm{CH}_{2}\right), 1.85$ (q, $\left.J=6.6 \mathrm{~Hz}, 2 \mathrm{H}, \mathrm{Ar}-\mathrm{O}-\mathrm{C}-\mathrm{CH}_{2}\right), 4.04\left(\mathrm{t}, 2 \mathrm{H}, J=6.8 \mathrm{~Hz}, \mathrm{O}-\mathrm{CH}_{2}\right)$, $7.05(\mathrm{~d}, 2 \mathrm{H}, J=8.8 \mathrm{~Hz}, \mathrm{Ar}-\mathrm{H}$ at C-3' and C-5'), $7.40(\mathrm{~d}, 2 \mathrm{H}, J=$ $9.0 \mathrm{~Hz}$, naphthalene ring system at C-3" and C-4"), 7.46-7.56 $(\mathrm{m}, 4 \mathrm{H}$ of naphthalene ring system at $\mathrm{C}-5$ ", $\mathrm{C}-6$ ", $\mathrm{C}-7$ " and $\mathrm{C}-8$ "), $7.65(\mathrm{~s}, 1 \mathrm{H}$ of naphthalene ring system at $\mathrm{C}-1 "), 7.83-8.06(\mathrm{~m}$, $4 \mathrm{H}, \mathrm{Ar}-\mathrm{H}$ at C-2, C-6, C-2' and C-6'), $8.38(\mathrm{~d}, 2 \mathrm{H}, J=8.9 \mathrm{~Hz}$, Ar-H at C-3 and C-5); IR (KBr) v: 929, $1724(\mathrm{COO}), 1601(\mathrm{~N}=\mathrm{N})$, $1583,1467,1251,1143,880,839,742 \mathrm{~cm}^{-1}$. Anal. calcd for $\mathrm{C}_{31} \mathrm{H}_{32} \mathrm{O}_{3} \mathrm{~N}_{2}$ : C 77.50, H 6.66, N 5.83; found C 77.23, H 6.16, N 5.56 .

(E)-naphthalen-2-yl4-(4-n-hexadecyloxyphenylazo)benzoat e: ${ }^{1} \mathrm{H}$ NMR $\left(\mathrm{CDCl}_{3}, 400 \mathrm{MHz}\right) \delta: 0.88\left(\mathrm{t}, 3 \mathrm{H}, J=6.6 \mathrm{~Hz}, \mathrm{CH}_{3}\right)$, $1.20-1.76\left(\mathrm{~m}, 26 \mathrm{H}, 13 \times \mathrm{CH}_{2}\right), 1.85(\mathrm{q}, 2 \mathrm{H}, J=6.7 \mathrm{~Hz}$, Ar-O-C-CH $), 4.13\left(\mathrm{t}, 2 \mathrm{H}, J=6.8 \mathrm{~Hz}, \mathrm{O}-\mathrm{CH}_{2}\right), 7.05(\mathrm{~d}, 2 \mathrm{H}, J=$ $8.8 \mathrm{~Hz}, \mathrm{Ar} \mathrm{H}$ at $\mathrm{C}-3^{\prime}$ and $\left.\mathrm{C}-5^{\prime}\right), 7.40(\mathrm{~d}, 2 \mathrm{H}, J=8.8 \mathrm{~Hz}$, naphthalene ring system at C-3" and C-4"), 7.46-7.56 (m, 4H 
Table 1 Transition temperatures $\left({ }^{\circ} \mathrm{C}\right)^{a}$ and enthalpies $(\mathrm{J} / \mathrm{g})^{b}$ of the series I \& II compounds

\begin{tabular}{|c|c|c|c|c|c|c|c|c|}
\hline Compounds & $\begin{array}{c}\mathrm{R}=\mathrm{C}_{n} \mathrm{H}_{2 n+1} \\
n=\end{array}$ & $\mathrm{Cr}$ & \multicolumn{2}{|c|}{ SmA } & & \multicolumn{2}{|l|}{$N$} & I \\
\hline \multicolumn{9}{|l|}{ Series I } \\
\hline 1 & 1 & - & 144 & - & - & $\bullet$ & 273 & - \\
\hline 2 & 2 & $\bullet$ & 134 & - & - & - & 272 & • \\
\hline 3 & 3 & $\bullet$ & $\begin{array}{c}145 \\
{[98.42]^{c}}\end{array}$ & - & - & $\bullet$ & $\begin{array}{c}251 \\
{[1.04]}\end{array}$ & • \\
\hline 4 & 4 & $\bullet$ & 143 & - & - & $\bullet$ & 260 & $\bullet$ \\
\hline 5 & 5 & • & 132 & - & 142 & • & 257 & • \\
\hline 6 & 6 & $\bullet$ & 130 & $\bullet$ & 160 & • & 251 & • \\
\hline 7 & 7 & $\bullet$ & 126 & $\bullet$ & 167 & $\bullet$ & 237 & $\bullet$ \\
\hline 8 & 8 & $\bullet$ & 122 & • & 175 & • & 236 & • \\
\hline 9 & 10 & $\bullet$ & 115 & $\bullet$ & 181 & - & 229 & $\bullet$ \\
\hline 10 & 12 & $\bullet$ & 120 & $\bullet$ & 180 & $\bullet$ & 228 & $\bullet$ \\
\hline 11 & 14 & $\bullet$ & 100 & $\bullet$ & 185 & - & 204 & $\bullet$ \\
\hline 12 & 16 & $\bullet$ & 97 & • & 187 & & & $\bullet$ \\
\hline
\end{tabular}

Series II

\begin{tabular}{|c|c|c|c|c|c|c|c|c|}
\hline 13 & 1 & $\bullet$ & 183 & - & - & $\bullet$ & 280 & $\bullet$ \\
\hline 14 & 2 & $\bullet$ & 180 & - & - & $\bullet$ & 277 & - \\
\hline 15 & 3 & $\bullet$ & 173 & - & - & $\bullet$ & 284 & - \\
\hline 16 & 4 & $\bullet$ & 175 & - & - & $\bullet$ & 273 & - \\
\hline 17 & 5 & $\bullet$ & 146 & - & - & $\bullet$ & 270 & - \\
\hline 18 & 6 & $\bullet$ & 145 & - & - & $\bullet$ & 250 & $\bullet$ \\
\hline 19 & 7 & - & 142 & $(\bullet$ & $140)^{d}$ & • & 237 & - \\
\hline \multirow[t]{2}{*}{20} & 8 & - & 138 & • & 150 & $\bullet$ & 220 & $\bullet$ \\
\hline & & & {$[66.63]^{c}$} & & {$[2.14]$} & & [1.50] & \\
\hline 21 & 10 & $\bullet$ & 135 & $\bullet$ & 160 & $\bullet$ & 211 & $\bullet$ \\
\hline 22 & 12 & - & 121 & $\bullet$ & 166 & • & 205 & - \\
\hline 23 & 14 & $\bullet$ & 117 & $\bullet$ & 165 & $\bullet$ & 196 & $\bullet$ \\
\hline 24 & 16 & $\bullet$ & 114 & $\bullet$ & 172 & $\bullet$ & 193 & • \\
\hline
\end{tabular}

${ }^{a}$ The transition temperatures were determined by the polarizing optical microscopy; ${ }^{b}$ The enthalpy values are enclosed in square brackets; ${ }^{c}$ Total enthalpy including any other $\mathrm{Cr}-\mathrm{Cr}$ transition; ${ }^{d}()=$ monotropic value; $\mathrm{Cr}=$ crystal; $\mathrm{SmA}=$ smectic $\mathrm{A}$ phase; $\mathrm{N}=$ nematic phase; I = isotropic liquid state; - = phase exists; - = phase does not exists. 


\section{Report}

of naphthalene ring system at C-5," C-6", C-7", and C-8"), 7.65 (s, $1 \mathrm{H}$ of naphthalene ring system at $\mathrm{C}-1 "), 7.84-8.06(\mathrm{~m}, 4 \mathrm{H}$, Ar-H at C-2, C-6, C-2' and C-6'), 8.38 (d, 2H, J = 9.0 Hz, Ar-H at C-3 and C-5); IR (KBr) v: 2955, 1730 (COO), $1603(\mathrm{~N}=\mathrm{N}), 1585$, $1464,1288,1153,840 \mathrm{~cm}^{-1}$. Anal. calcd for $\mathrm{C}_{39} \mathrm{H}_{48} \mathrm{O}_{3} \mathrm{~N}_{2}$ : C 79.05, H 8.10, N 4.72; found C 79.31, H 8.18, N 4.70 .

\section{Results and Discussion}

\section{Optical microscopy studies}

As a preliminary investigation, the mesophases exhibited by compounds of series I and II were concluded by the optical microscopic studies. On cooling, isotropic liquids of series I compounds $(n=1-14)$ formed small droplets that coalesced to the classical schileren texture of the nematic phase (Figure 1a) and $n$-pentyloxy to $n$-tetradecyloxy derivatives on further cooling exhibited focal conic texture characteristic of smectic $A$ mesophase (Figure 1b). On cooling, isotropic liquids of $n$-hexadecyloxy derivatives exhibited only focal conic texture characteristic of smectic A mesophase.

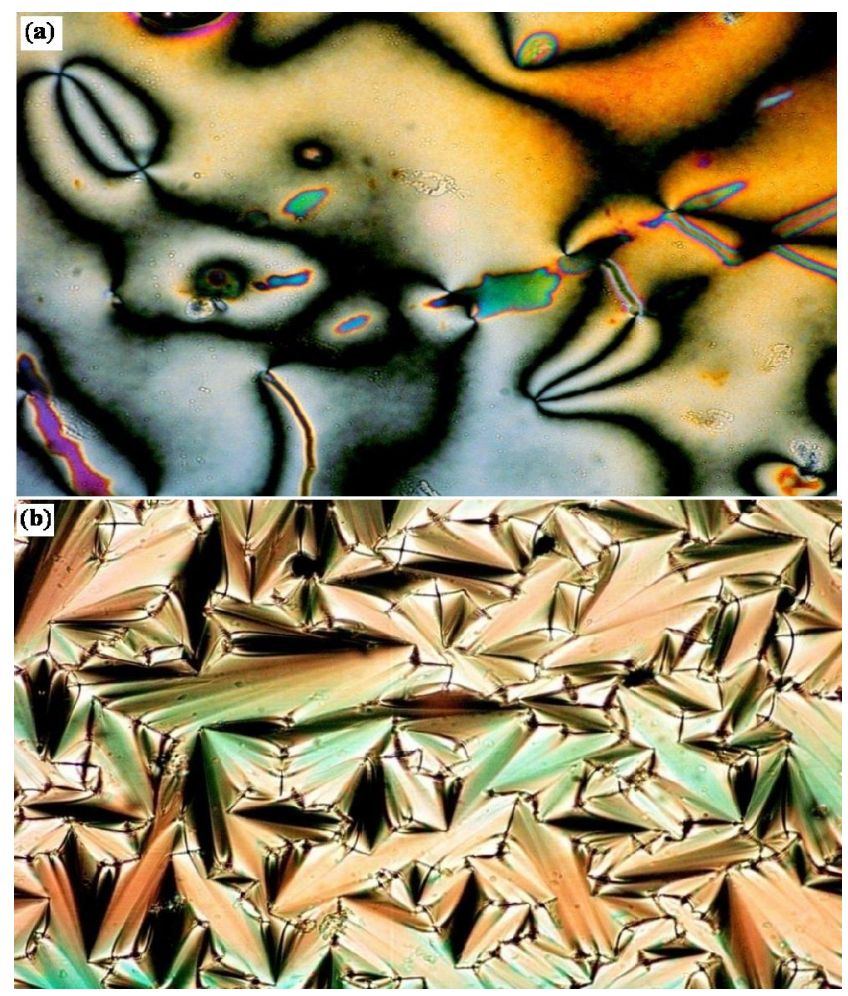

Figure 1 Microphotograph of (a) schlieren texture of nematic mesophase (series I; $n=14$ ) at $190^{\circ} \mathrm{C}$ and (b) focal conic texture of SmA mesophase (series I; $n=14$ ) at $125^{\circ} \mathrm{C}$.

On cooling, isotropic liquids of series II, all the compounds ( $n=1-16)$ formed small droplets that coalesced to the classical schileren texture of the nematic phase and $n$-heptyloxy to $n$-hexadecyloxy derivatives on further cooling, exhibited focal conic texture characteristic of smectic A mesophase.

\section{Differential scanning calorimetry (DSC) studies}

Calorimetry is a valuable method for the detection of liquid crystalline phase transitions. It yields quantitative results. Therefore, conclusion may be drawn concerning the nature of the phases, which participate in the transition. The DSC data of $n$-propyloxy derivative of series I and $n$-octyloxy derivative of series II as a representative member are listed in Table 1.

\section{Mesomorphic behavior}

\section{Series I}

(E)-naphthalen-2-yl 4-(4-n-alkoxybenzylideneamino)-benzoates: All the twelve synthesized compounds exhibit mesomorphism. Methoxy to $n$-tetra decyloxy derivatives exhibited enantiotropic nematic mesophase. The SmA mesophase commences from $n$-pentyloxy derivative as an enantiotropic and persists up to the $n$-hexadecyloxy homologue. The plot of transition temperatures against the number of carbon atoms in the alkyl chain exhibited rising tendency in SmA-N transition temperatures (Figure 2). $\mathrm{N}-\mathrm{I}$ transition temperatures decrease with the increase in the length of terminal alkoxy chain and exhibit a usual odd-even effect. The crystal melting transition temperatures decrease with the increase in the length of terminal alkoxy chain with the exception of compounds 3,4 and 12 in series I.

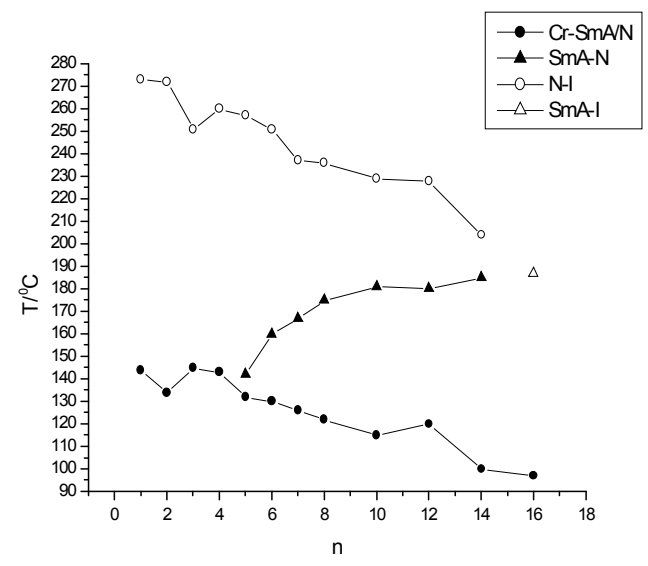

Figure 2 The phase behavior for series I compounds.

\section{Series II}

(E)-naphthalen-2-yl 4-(4-n-alkoxyphenylazo)-benzoates: All the twelve synthesized compounds exhibit enantiotropic nematic mesophases. SmA mesophase commences from $n$-heptyloxy as monotropy and persists up to the last homologous synthesized. The plot to transition temperatures against the number of carbon atoms in the alkyl chain exhibited rising tendency in SmA-N transition temperatures (Figure 3). The crystal-melting transition temperatures with the exception of $n$-butyloxy derivative and $\mathrm{N}$-I transition temperatures decrease with the increase in the length of terminal alkoxy chain.

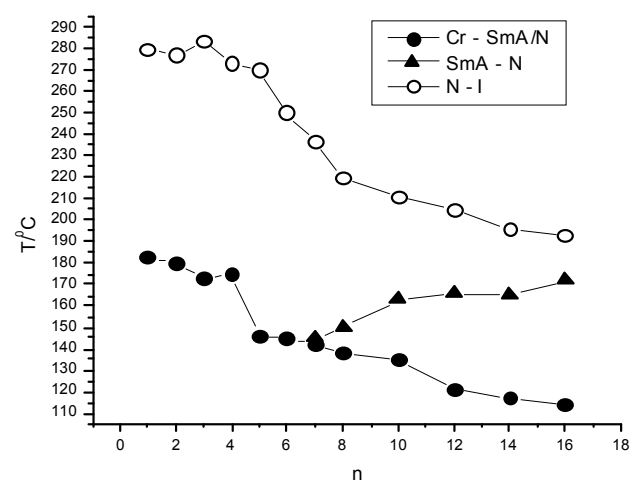

Figure 3 The phase behavior for series II compounds. 
Table 2 The mesophase length, phase transitions, and comparative molecular structure of $n$-dodecyloxy derivative of series I, II and A to $E$

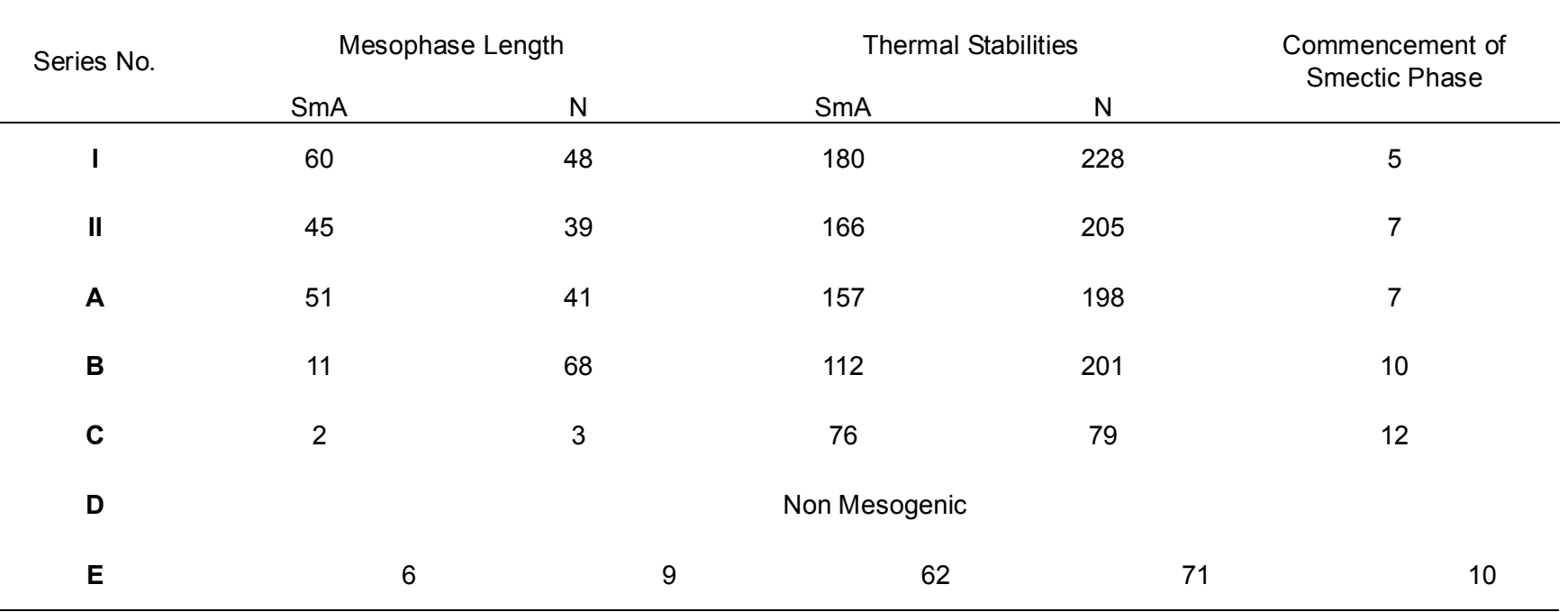

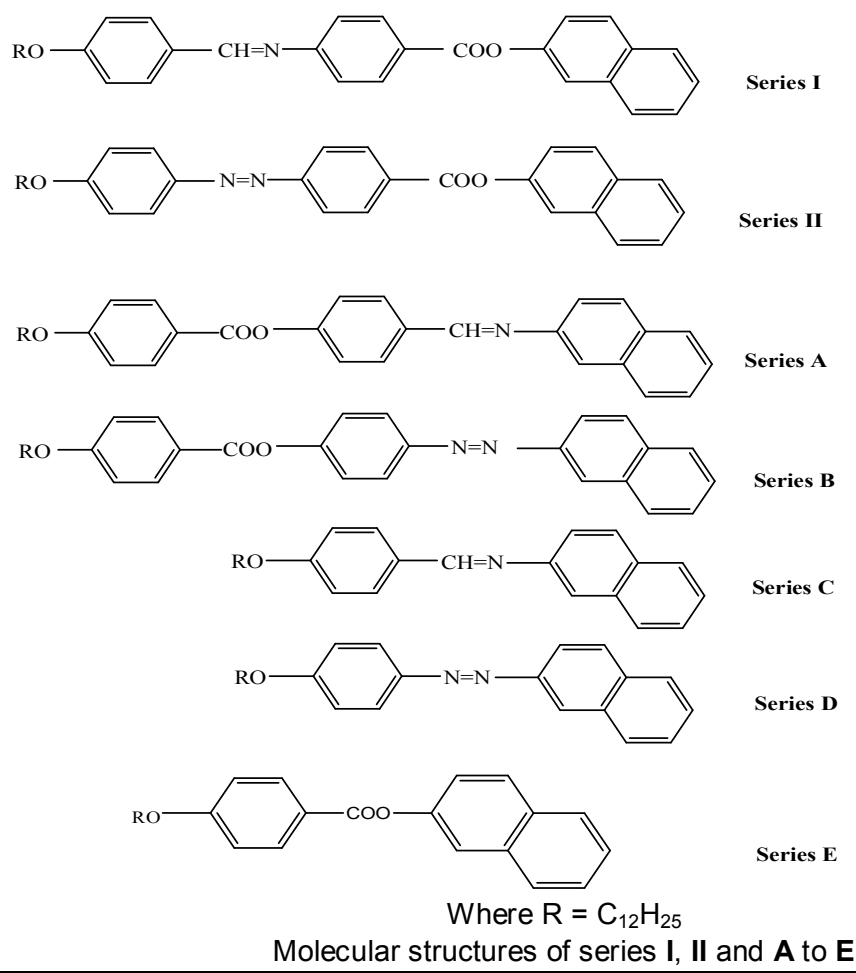

It is now well established that the thermotropic liquid crystals are highly sensitive to their molecular constitution. To determine the effect of alterations in the molecular core on the mesogenic properties of a compound, the thermal stability and mesophase length as a measure of mesomorphism can be correlated with the molecular constitution of the compounds. Table 2 summarizes comparison of mesophase range, transition temperatures and molecular structure of the $n$-dodecyloxy derivative of present series I \& II as well as structurally related known series $\mathbf{A},{ }^{[19]} \mathbf{B},{ }^{[21]} \mathbf{C},{ }^{[19]} \mathbf{D},{ }^{[21]}$ and $\mathbf{E} .{ }^{[33]}$

Table 2 shows that the smectic mesophase length of series $\mathrm{I}$ is higher by $15^{\circ} \mathrm{C}$, and the smectic thermal stability is higher by $14{ }^{\circ} \mathrm{C}$. The nematic mesophase length and nematic mesophase thermal stability of series I are higher by 9 and $23^{\circ} \mathrm{C}$ than series II. The molecular structures of both these compounds differ only at one central linkage. Series I have azomethine
$(\mathrm{CH}=\mathrm{N})$ central linkage, whereas series II have azo $(\mathrm{N}=\mathrm{N})$ central linkage. Generally, incorporation of ester and azomethine linkage increases the acoplanarity of the system. ${ }^{[38,39]}$ Hence, series I will be more acoplaner due to the presence of azomethine central linkage. This acoplanarity gives probably such a packing to the molecules, so that the smectic and nematic mesophase length as well as thermal stabilities of series I becomes higher than that of series II.

Table 2 shows that the smectic mesophase length of series $\mathrm{I}$ is higher by $54^{\circ} \mathrm{C}$ and the smectic thermal stability is higher by $118{ }^{\circ} \mathrm{C}$. The nematic mesophase length thermal stability of series $\mathbf{I}$ is higher by 39 and $157^{\circ} \mathrm{C}$ than series $\mathbf{E}$, respectively. Reference to the molecular structure of both these compounds shows that the both the compounds differ in the number of benzene ring and central linkage. Series I are longer and more polarizable in comparison with series $\mathbf{E}$ due to the presence of 


\section{Report}

additional azomethine central linkage and benzene moiety, which is responsible for the greater mesophase length and higher thermal stabilities of series $\mathbf{I}$. This is also reflected in the comparison of series II and E. The smectic mesophase length of series II is higher by $39^{\circ} \mathrm{C}$, and the smectic thermal stability is higher by $104{ }^{\circ} \mathrm{C}$. However, the nematic mesophase length and thermal stability of series $\mathrm{E}$ are higher by 30 and $134{ }^{\circ} \mathrm{C}$ than series $\mathbf{E}$.

Compared with series $\mathbf{A}$, the smectic and nematic thermal stability of series I are higher by 23 and $30^{\circ} \mathrm{C}$, respectively. The only difference in the geometry of the two series lies in the position of central linkages. In series I, the phenyl ring and the naphthyl ring are linked by $\mathrm{COO}$ linkage, where they are joined by $\mathrm{CH}=\mathrm{N}$ central linkage in series $\mathbf{A}$. Due to presence of flexible ester group near the naphthalene moiety, the molecules are packed in such a way. Therefore, its thermal stability becomes little higher in comparison with series $\mathbf{A}$. This is also reflected in the comparison of series II and $\mathbf{B}$. Compared to series $\mathbf{B}$, the smectic and nematic thermal stability of series II is higher by 54 and $4{ }^{\circ} \mathrm{C}$, respectively. The only difference in the geometry of the two series lies in the position of central linkages. In series II, the phenyl ring and naphthyl ring are linked by COO linkage, where they are joined by $\mathrm{N}=\mathrm{N}$ central linkage in series $\mathrm{B}$.

Table 2 indicates that smectic mesophase length and thermal stability of series I are higher by 58 and $104{ }^{\circ} \mathrm{C}$, respectively. The nematic mesophase length and thermal stability are also higher by 45 and $149^{\circ} \mathrm{C}$ in comparison with series C, respectively. The molecules of series I and $\mathbf{C}$ are different in the number of phenyl ring and central linkage. The molecule of series $\mathbf{I}$ is longer and polarizable due to the additional phenyl ring and an ester central linkage, which is responsible for the greater mesophase length and higher thermal stability for series $\mathbf{I}$. This is also reflected in comparison of series II and D. Series II exhibit mesomorphic properties with good mesophase length and higher thermal stabilities, however, series $\mathbf{D}$ is nonmesogenic

\section{Conclusions}

Two new mesogenic homologous series containing naphthalene moiety were synthesized. All the synthesized compounds exhibit mesomorphism. The present two series exhibit higher thermal stabilities because of presence of flexible ester linkage at the naphthalene moiety in comparison with the analogous mesogenic homologous series of the naphthalene derivatives having azo or azomethine central linkage at the naphthalene moiety. The addition of phenyl ring and azo/ azomethine central linkage resulted in the compound with greater mesophase length and higher thermal stability than ester central linkages.

\section{Acknowledgement}

The authors thank specially Prof. Keyur Shah in Shri M. M. Patel Institute of Sciences and Researches and Prof. N. D. Kulkarni in M. S. University of Baroda for providing research facilities. One of the authors, H. N. Patel, thanks GUJCOST (GUJCOST/MRP/2016-17/441) for the grant of minor research project, entitled "Synthesis, Characterization and Mesomorphic Properties of Novel Liquid Crystalline Materials".

\section{Author Contributions}

Both the authors have contributed equally.

\section{Supporting Information}

Supporting information for this article is available on the WWW under www.genchemistry.org/EN/10.21127/yaoyigc201 80010.

\section{Special Issue}

This paper is dedicated to the special issue of "Liquid Crystals".

\section{References}

[1] Demus, D.; Zaschke, H. Flussige Kristalle in Tabllenll, VEBDeutscher Verlagfur Grundstoffindustrie, Leipzig, 1984.

[2] Vill, V. Liq.Cryst.2.0 Database of Liquid Crystalline Compoundsfor Personal Computers, FijitsuKyushu System(KOS)Ltd., Fukuoka, LCl, Hamburg 1996

[3] Wiegand, C. Z. Naturforschung 1954, B9, 516.

[4] Gray, G. W.; Jones, B. J. Chem. Soc. 1954, 608.

[5] Coates, D.; Gray, G. W. Mol. Cryst. Liq. Cryst. 1978, 41, 197.

[6] Dave, J. S.; Kurian, G.; Joshi, B. C. Liq. Cryst. In Proceedings of the International Conference on Liquid Crystals, Ed.: Chandrasekhar, S., Heyden, London, 1980, p. 54.

[7] Dave, J. S.; Kurian, G. Mol. Cryst. Liq. Cryst. 1977, 42, 193; Pranama, 1975, 1, 427.

[8] Dave, J. S.; Kurian, G.; Prajapati, A. P.; Vora, R. A. Mol. Cryst. Liq. Cryst. 1971, 14, 307; Curr. Sci. 1972, 41, 415; Indian J. Chem. 1972, 10, 754.

[9] Dave, J. S.; Prajapati, A. P. Pramana 1975, 1, 735

[10] Dave, J. S.; Kurian, G.; Prajapati, A. P. Mol. Cryst. Liq. Cryst. 1983 $99,385$.

[11] Malthete, J.; Billard, J.; Jacques, J.; Rhebald, C. S. Acad. Sci. Paris C 1975, 281, 333.

[12] Hsu, H. F.; Lai, Y. H.; Lin, S. Y.; Lin, W. C.; Chen, J. F. Liq. Cryst. 2003, 30, 325

[13] (a) Kohout, M.; Svoboda, J.; Novotná, V.; Pociecha, D.; Glogarová, M.; Gorecka, E. J. Mater. Chem. 2009, 19, 3153; (b) Kohout, M.; Svoboda, J.; Novotná, V.; Glogarová, M., Pociecha, D. Liq. Cryst. 2010, 37, 987; (c) Kovářová, A.; Kozmík, V.; Svoboda, J.; Novotná V.; Glogarová, M.; Pociecha, D. Liq. Cryst. 2012, 39, 755.

[14] Rahman, M. L.; Yusoff, M. M.; Hegde, G.; Abdul Malek, M. N. F.; Samah, N. A.; Srinivasa, H. T.; Kumar, S. J. Chin. Chem. Soc. 2014, 61, 571

[15] Simion, A.; Huzum, C. C.; Carlescu, I.; Lisa, G.; Balan, M.; Scutaru, D. J. Serb. Chem. Soc. 2015, 80, 673.

[16] Kozmík, V.; Rodinová, E.; Prausová, T. Department of Organic Chemistry, University of Chemistry and Technology Prague, Prague 6, Czech Republic; Svoboda, J.; Novotná, V.; Gorecka, E.; Pociecha, D. Liq. Cryst. 2018, 45, 746

[17] Srinivasa, H. T. Liq. Cryst. 2017, 44, 1384.

[18] Rahman, M. L.; Hegde, G.; Yusoff, M. M.; Malek Muhammad, N. F. A.; Srinivasa, H. T.; Kumar, S. New J. Chem. 2013, 37, 2460.

[19] Vora, R. A.; Prajapati, A. K. Liq. Cryst. 1998, 25, 567.

[20] Prajapati, A. K. Mol. Cryst. Liq. Cryst. 2000, 348, 65.

[21] Vora, R. A.; Prajapati, A. K. In Proceeding of the 5th National Seminaron Liquid Crystals, Patiala, India, 1996, p. 97.

[22] Prajapati, A. K. Liq. Cryst. 2000, 27, 1017.

[23] Prajapati, A. K.; Pandya, H. M. Mol. Cryst. Liq. Cryst. 2003, 393, 31; Prajapati, A. K.; Pandya, H. M.; Bonde, N. J. Chem. Sci. 2004, 116, 227.

[24] Jadav, N. D.; Prajapati, B. A.; Prajapati, A. K. Mol. Cryst. Liq. Cryst. 2003, 399, 53

[25] Prajapati, A. K.; Thakkar, V.; Bonde, N. Mol. Cryst. Liq. Cryst. 2003 93, 41.

[26] Teucher, I.; Paleos, C. M.; Labes, M. M. Mol. Cryst. Liq. Cryst. 


\section{General Chemistry}

1970, 11, 187

[27] Hoshino, N. Coord. Chem. Rev. 1998, 174, 77.

[28] Ed.: Serrano, J. L. Metallomesogens: Synthesis, Properties and Applications, Wiley-VCH, Weinheim, Germany, 1996

[29] Bruce, D. W. Inorganic Materials, Bruce, D. W.; O'Hare, D. 2nd Edn, Wiley, Chichester, 1996, p. 429.

[30] Giroud-Godquin, A. M. In Handbook of Liquid Crystals. Vol. 2B, Eds.: Demus, D.; Goodby, J.; Gray, G. W.; Spiess, H. W.; Vill, V. Chapter XIV, Wiley-VCH, Weinheim, Germany, 1998.

[31] Donnio, B.; Bruce, D. W. Struct. Bond. 1999, 95, 193.

[32] Prajapati, A. K.; Bonde, N. Liq. Cryst. 2006, 33, 1189.

[33] Patel, H. N.; Prajapati, A. K. Mol. Cryst. Liq. Cryst. 2017, 643, 106.

[34] Gray G. W.; Jones, B. J. Chem. Soc. 1954, 1467.
[35] Dave, J. S.; Patel, P. R. Mol. Cryst. Liq. Cryst. 1966, 2,115

[36] Hassen, A.; Alexanian, V. Tetrahedron Lett. 1978, 4475.

[37] Jadav, N. D. Ph.D. Thesis, The M. S. University of Baroda, Vadodara, India, 1979.

[38] Hornreich, R. M.; Shtrikman, S. Phys. Rev. A 1981, 24, 605; 1983, 28, 1791.

[39] Stegmeyer, H.; Porshch, F. Phy. Rev. A 1984, 30, 3369; Liq. Cryst. $1987,2,395$

Received March 31, 2018

Accepted April 24, 2018 